which in a pronounced degree are restricted to the Arctic sea areas. Indeed Dr. Jespersen states that "it is certainly a question whether among the oceanic copepods there are any distinct arctic forms at all".

The most frequent species were Calanus finmarchicus, Calanus hyperboreus, Metridia longa and young stages of the genus Pareuchota. Calanus finmarchicus predominates in the hauls from the south of Davis Strait and the numbers are considerably reduced in Baffin Bay. In Smith Sound, much farther north, it is again abundant in the surface layers. Calanus hyperboreus, which likes cold water, is found only in small quantities south of Davis Strait, in the Strait itself in the upper layers being more abundant and in Baffin Bay present in small quantities. Metridia longa occurs in small quantities south of the Davis Strait and in the upper layers of the Strait itself, but occurs in fairly large numbers in Baffin Bay. Pareuchceta in its young stages is found in the water south of Davis Strait and only in small quantities in the Strait itself and in the more northern parts investigated.

Details of distribution and biology of all the species are given whenever possible with much interesting information, and many species are shown to have a more northerly distribution than was known before. A series of tables and curves is also provided. One new species was found, Euchoeta Wilsoni, and this is represented by only one specimen.

\title{
All-Metal Radio Receiving Valves
}

$I^{\mathrm{T}}$ will be recalled that about two years ago the 'Catkin' series of receiving valves was first produced in Great Britain (see NATURE, 131, 735 ; 1933). In the construction of this valve, the amount of glasswork was reduced to a considerable extent, the upper portion of the envelope being formed of the eylindrical copper anode, which was sealed to the lower glass portion by a vacuum-tight joint. Now, an entirely new series of literally all-metal receiving valves is announced by the General Electric Co. of America, and brief details of these were given by the New York representative of the Wireless World in the issue of that journal of April 19. These new valves employ a cylindrical outer shell of stecl or iron welded to a metal base which rigidly supports the electrode system. The lead-in wires from the electrodes are strung through beads of glass, which are then placed in eyelets of a new alloy known as Fernico, which lines the holes in the base of the valve. The assembly is then passed through a gas flame which fuses the glass beads so that they fill the eyelets. Fernico is an alloy of iron, nickel and cobalt which has the same coefficient of expansion as the beads of glass employed, so that the seal is accom. plished without setting up strains in the fusing process. After the electrode system has been attached to the leads, the metal outer shell is placed over the structure and welded to the base. The valve is now exhausted through this metal tube, which is then clamped, welded and cut off at the appropriate time.

The use of an all-metal construction enables the valves to be made smaller in dimensions than existing glass valves, with corresponding reduction in lengths of leads and inter-electrode capacitances. The valves may therefore be of higher amplification factors with out instability, and should retain their efficiency at shorter wave-lengths than existing types. Further, since the metal shell completely surrounds the valve and is maintained at earth potential, there will be no necessity for shielding the valve after it is placed in its socket in the receiver. At the present time, six types of all-metal valve have been put into production at the R.C.A. Manufacturing Co., which will make the valves for the General Electric Co. It is expected that now receivers designed round the metal valve will be produced by the autumn of this year.

\section{Physical Methods in the Study of Earth Structure}

$\mathrm{T}$ HE increasing specialisation of science and its literature inspires an ever-growing demand for expositions of separate branches in terms suitable for workers in other fields. The effort to prepare such accounts is often beneficial to those who provide as well as to those who hear or read them; but some stimulus for their provision is needful, and notable among the available effective stimuli are the endowed annual lectureships of such bodies as the Institution of Civil Engineers. This is well exemplified in the forty-first James Forrest Lecture, delivered to that Institution on May 7 by Prof. O. T. Jones, who took geophysics as his subject.

The choice by a geologist to lecture on geophysics might in past years have led to a passionate or scornful attack on the geological ignorance of geophysicists; but even in this age of tolerance, Prof. Jones is notable among geologists for his sense of the importance of physical methods in studying the problems of the earth. He has, in fact, produced an admirably clear account of the subject, after modestly disclaiming any rôle save that of the exponent. So calm is the 'atmosphere' of his address that the geophysicist may even feel a craving for at least some more distinctively geological criticism or flavour. But in the closing part of the address Prof. Jones made a most interesting reference to a British problem that is of interest alike to geologists, geophysicists and engineers.

In many parts of the British Isles, Prof. Jones stated, there are known to be many deep rock channels that are so filled with various materials that their existence has not been suspected until engineering explorations for railways, roads, tunnels or sites for reservoirs have revealed them. Some of them are known to be post-glacial : others, being filled with glacial drift, must be pre-glacial. It is still uncertain whether these latter are due to normal river erosion, in which case their gradient must have been continuously downward to the sea-level of their period; or whether they have been excavated by streams flowing below the ice, in which case they 